\title{
Thermomechanical and Electrical Properties of Fabric Reinforced Laminates with Filled Stratified Epoxy Matrix
}

\begin{abstract}
MARINA BUNEA*, RADU BOSOANCA, ADRIAN COJ AN, IULIAN GABRIEL BIRSAN
Dunarea de Jos University of Galati, Border Faculty of Humanities, Economics and Engineering, 47 Domneasca Str., 800008, Galati, Romania

The thermal coefficient of linear expansion, the electrical conductivity and dielectric permittivity of fabric reinforced hybrid composites with filled stratified epoxy matrix were investigated. The measurements of electrical conductivity and dielectric permittivity had been performed, using standard method regarding electrical resistance and electrical capacity. In order to point out the effect of filler and of the spatial distribution of reinforcement layers, the medial layer of fabric was especially prepared by introducing copper wires in the woven. So, the medial layer is made of different types of tows (carbon, aramid, glass). This attempt is made in order to design a composite able to provide information about its state during various loading. The results showed that the fillers did not improve the electrical parameters of epoxy matrix, but they led to reduce the thermal coefficient of linear expansion. The thermal and electrical behavior of hybrid composites varied in dependence of number of carbon layers and fiber orientation.
\end{abstract}

Keywords: epoxy composite, hybrid material, electrical conductivity, dielectric permittivity, thermal expansion coefficient

Polymer composite materials are a particular interest in many industries for their mechanical, thermal and electrical properties design, as opposed to metallic materials. To improve some properties of a composite material for a specific purpose, in its structure might be used different types of fabrics as reinforcement for polymer matrix composites, like glass, carbon, aramid and mixed fabrics and various modifications agents that are able to induce controlled modifications of polymer properties.

Generally, to get good results for some specific responses of composites various types of reinforcement are used. For instance: aramid fibers to obtain a material with good shock resistance; glass fibers to obtain a material with good tensile and compressive properties; and carbon fibers to form a material with good bending properties but also with better electrical properties (tacking into account the fact that these fibers are showing higher electric conductivity). As it is well known it is quite difficult to maintain the regulate distribution of fibers during forming maneuvers and, in the case of thermoset polymers, the use of fabrics is recommended. So the reinforcement of a thermoset polymer matrix composite may contain various types of fabrics (made of various types of fibers) that can be distributed on a stack sequence imposed by the need of requiring some special properties. For example, the use of fabrics as reinforcement for polymer matrix composites could lead to an improvement of mechanical properties and could affectelectrical or thermal properties, or inverse [1].

The composites properties could be modified, also, if will be using into the polymer matrix composition different fillers. Starch, for instance, is often used due to its capacity to disperse into a liquid phase and its use into epoxy resins was proved to have a beneficial effect on other fillers uniform dispersion [2, 3]. Using fillers like carbon black and ferrites, it is possible to improve electromagnetic properties and using talc, carbon whiskers and clay to improve dielectric properties [1]. But to obtain the desired results, the most important are uniform distribution of powders in matrix and the properties of interphases between components $[4,5]$.
Initially, the aim of the research was to design and to form multifunctional materials. Different types of fabrics (carbon fibers, glass fibers and aramid fibers) and three different mixtures of fillers to improve the mechanical, thermal and electrical properties were used. Also, it was realized a hybrid fabric, which contains copper wire for improving the electrical conductivity of materials. For mixtures of fillers were used: the potatoes starch, aramid powder, carbon black, barium ferrite, and carbon and glass whiskers. The potatoes starch was used because it does not affect the proprieties of materials. The aramid powder, carbon and glass whiskers [6-9] were used for improving the mechanical properties and impact resistance. The carbon black [10-13], carbon whiskers [14, 15] and barium ferrite $[16,17]$ were used for improving the thermal and electromagnetic properties. The fillers were chosen to provide connections between the components of matrices, taking into account, also, the fabric type used for each layer of the laminate.

The purpose of this paper is to present the thermal and electrical behavior of composite materials. These materials are laminate like materials - being formed by wet-laying method-and are realized with differentstacking sequences and various filled polymer layers between fabrics (all the polymer layers are based on the same polymer but this polymer is modified by dispersing various fillers into it). The effect of stacking sequence and of the presence of the fillers on thermos-mechanical (linear coefficient of thermal expansion - perpendicular on the reinforcement plane) and electromagnetic properties (surface and bulk electric conductivity and surface and bulk dielectric permittivity) were analyzed.

\section{Experimental part}

\section{Materials and methods}

The use of fabrics as reinforcements for polymer matrix composites is recommended by their ability to form sinuous and complicated surfaces keeping the regulated distribution of the fibers. The wet-lay-up method of composite forming allows obtaining of materials with the same matrix in all the volume (between and through fabrics 
layers) unlike the traditional laminated composites, where the bonds between layers are obtained using adhesives (for thermoset matrix laminae) or thermal treatments (for thermoplastic matrix laminae). Stratified materials with the same polymer in all the volume respond different from laminated at all the external solicitations-thermal, electrical, mechanical etc. For this study epoxy resin was used as matrix and various fabrics as reinforcement in order to obtain stratified materials with different properties.

A special type of fabric was realized and was used as medial layer $[18,19]$. Starting with a hybrid fabric made of aramid and carbon fiber tows in geometry $2 \times 1$ on weft direction and $1 \times 2$ on warp direction, each second aramid tow of the weft was replaced with a glass fiber tow together with a $0.2 \mathrm{~mm}$ diameter wire of tin covered copper, as it can be seen in figure 1 . Such as the final fabric was a simple hybrid plain type fabric with $270 \mathrm{~g} / \mathrm{m}^{2}$ specific density, but with three alternating kinds of tows on the weft direction, denoted $M$. All the other fabrics used were simple plain types as follows: A- aramid fiber fabric with $173 \mathrm{~g} / \mathrm{m}^{2}$ specific density; C - carbon fiber fabric with 160 $\mathrm{g} / \mathrm{m}^{2}$ specific density; 1G -glass fiber fabric with $163 \mathrm{~g} / \mathrm{m}^{2}$ specific density; 2G-glass fiber fabric with $390 \mathrm{~g} / \mathrm{m}^{2}$ specific density.

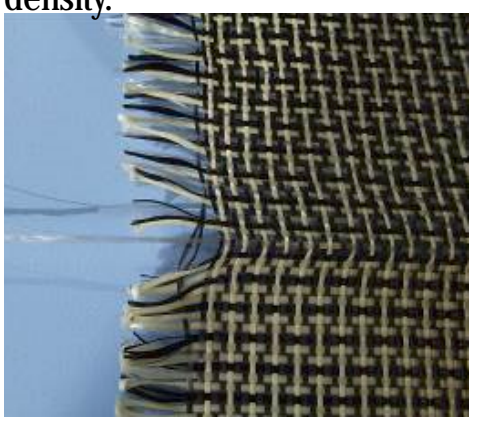

Fig. 1. The hybrid fabric with three alternating kinds of tows (aramid, carbon and glass) and wire of tin covered copper on the yarn direction

The matrix of all the four materials was made of epoxy resin system EPIPHEN RE4020-DE4020. To modify the basic properties of epoxy resins three powder mixtures had been used: MF1-10\% volume ratio of starch and 10\% volume ratio of carbon black; MF2- 5\% volume ratio of aramid powder, $5 \%$ volume ratio of starch, $5 \%$ volume ratio of carbon whiskers and $5 \%$ volume ratio of glass whiskers; MF3-10\% volume ratio of aramid powder and $10 \%$ volume ratio of barium ferrite. Table 1 shows the nature and orientation of each reinforcement layer and the type of filled epoxy matrix. So, MF1 matrix was used to imbue (prior to mold placement) for 01 to 03 and 15 to 17 layers of reinforcement, MF2 for 04 to 06 and 12 to 14 layers of reinforcement and MF3 for 07 to 11 layers of reinforcement.
The linear coefficient of thermal expansion was measured with TMA SDTA 840 thermo-mechanical analyzer and STARe software for acquisition and evaluation of data by heated from 30 to $200^{\circ} \mathrm{C}$ with $20^{\circ} \mathrm{C} / \mathrm{min}$. For thermosmechanical measurements specimens with $10 \times 5 \mathrm{~mm}$ dimensions were used.

The electromagnetic measurements were performed with Digital Protek 9216A LCR-meter instrument. The electrical conductivity and dielectric permittivity were measured at 1, 10 and $100 \mathrm{kHz}$ frequency and $1 \mathrm{~V}$ test voltage. The LCR-meter offers four modes of measurements: $R+Q$ (resistance + quality factor), $L+Q$ (inductance + quality factor), $C+D$ (capacitance $+1 / D)$ and $C+R$ (capacitance + resistance). For investigation of these electrical parameters, there were used plate specimens with $297 \times 210 \mathrm{~mm}$ dimensions.

\section{Results and discussions}

The investigation of linear coefficient of thermal expansion was made on ranges of linear portions of the dimension change vs. temperature curves. These portions indicate the linear thermal behavior of composites with the increasing of the temperature. So, for this investigation the values of the coefficient of thermal expansion were determined on two temperature intervals 40 to $60^{\circ} \mathrm{C}$ and 110 to $170^{\circ} \mathrm{C}$. Considering that the carbon, aramid and glass fibers are not changing their dimensions with the increasing of temperature, it was investigated, also, the thermal behavior of non-filled and filled matrices on $40^{\circ} \mathrm{C}$ to 60 and 110 to $170^{\circ} \mathrm{C}$ temperature ranges.

$$
\rightarrow-40-60^{\circ} \mathrm{C}-110-170^{\circ} \mathrm{C}
$$

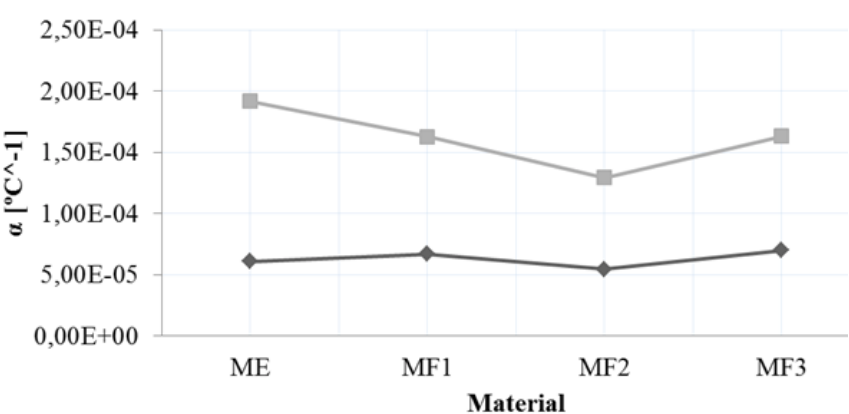

Fig. 2. Coefficient of thermal expansion for non-filled and filled epoxy system

As it can be seen in figure 2, on the $40-60^{\circ} \mathrm{C}$ temperature range the coefficient of linear thermal expansion of nonfilled epoxy matrix exhibits a lower value than those of epoxy matrix filled with starch, carbon black (MF1) and aramid powder, barium ferrite (MF3). But on this

Table 1

THE ARCHITECTURE OF FABRIC REINFORCED HYBRID COMPOSITES WITH FILLED STRATIFIED EPOXY MATRIX.

\begin{tabular}{|c|c|c|c|c|c|c|c|c|c|c|c|c|c|c|c|c|c|}
\hline \multirow{2}{*}{ 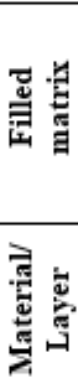 } & \multicolumn{3}{|c|}{$\begin{array}{c}\text { MF1 } \\
\text { (potatoes starch } \\
+ \text { carbon black) }\end{array}$} & \multicolumn{3}{|c|}{$\begin{array}{c}\text { MF2 } \\
\text { (aramid powder }+ \\
\text { potatoes starch }+ \\
\text { carbon whiskers + } \\
\text { glass whiskers) }\end{array}$} & \multicolumn{5}{|c|}{$\begin{array}{c}\text { MF3 } \\
\text { (aramid powder }+ \text { barium } \\
\text { ferrite) }\end{array}$} & \multicolumn{3}{|c|}{$\begin{array}{c}\text { MF2 } \\
\text { (aramid powder }+ \\
\text { potatoes starch }+ \\
\text { carbon whiskers + } \\
\text { glass whiskers) }\end{array}$} & \multicolumn{3}{|c|}{$\begin{array}{l}\text { MF1 } \\
\text { (Potatoes starch } \\
+ \text { carbon black) }\end{array}$} \\
\hline & 01 & 02 & 03 & 04 & 05 & 06 & 07 & 08 & 09 & 10 & 11 & 12 & 13 & 14 & 15 & 16 & 17 \\
\hline 1H & $\mathrm{CO}$ & $\mathrm{CO}$ & $\mathrm{A} 0$ & $1 \mathrm{G} 0$ & $2 \mathrm{G} 0$ & $1 \mathrm{G} 0$ & $\mathrm{~A} 0$ & $\mathrm{C} 0$ & M90 & $\mathrm{CO}$ & $\mathrm{A} 0$ & $1 \mathrm{G} 0$ & $2 \mathrm{G} 0$ & $1 \mathrm{G} 0$ & $\mathrm{~A} 0$ & $\mathrm{C} 0$ & $\mathrm{CO}$ \\
\hline $2 \mathrm{H}$ & $\mathrm{CO}$ & $\mathrm{C} 75$ & A15 & $1 \mathrm{G} 60$ & $2 \mathrm{G} 0$ & $1 \mathrm{G} 30$ & A45 & $\mathrm{CO}$ & M90 & $\mathrm{CO}$ & A45 & $1 \mathrm{G} 45$ & $2 \mathrm{G} 0$ & $1 \mathrm{G} 45$ & A15 & C75 & $\mathrm{CO}$ \\
\hline $3 \mathrm{H}$ & $\mathrm{CO}$ & $\mathrm{A} 0$ & $\mathrm{~A} 0$ & $1 \mathrm{G} 0$ & $2 \mathrm{G} 0$ & $1 \mathrm{G} 0$ & $\mathrm{CO}$ & $\mathrm{A} 0$ & M90 & $\mathrm{AO}$ & $\mathrm{C} 0$ & $1 \mathrm{G} 0$ & $2 \mathrm{G} 0$ & $1 \mathrm{G} 0$ & $\mathrm{~A} 0$ & $\mathrm{~A} 0$ & $\mathrm{CO}$ \\
\hline $4 \mathrm{H}$ & $\mathrm{CO}$ & A75 & A15 & $1 \mathrm{G} 60$ & $2 \mathrm{G} 0$ & $1 \mathrm{G} 30$ & $\mathrm{C} 45$ & $\mathrm{~A} 0$ & M90 & $\mathrm{A} 0$ & $\mathrm{C} 45$ & $1 \mathrm{G} 45$ & $2 \mathrm{G} 0$ & $1 \mathrm{G} 45$ & A15 & A75 & $\mathrm{CO}$ \\
\hline
\end{tabular}




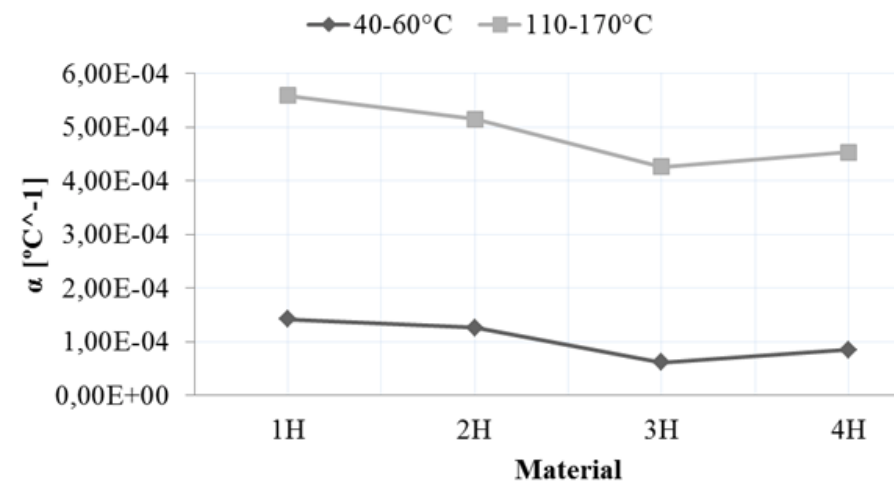

Fig. 3. Coefficient of thermal expansion for fabric reinforced hybrid composites with filled stratified epoxy matrix

$$
\leadsto \text { ME }-\mathrm{MF} 1 \multimap \mathrm{MF} 2 \multimap \mathrm{MF} 3
$$

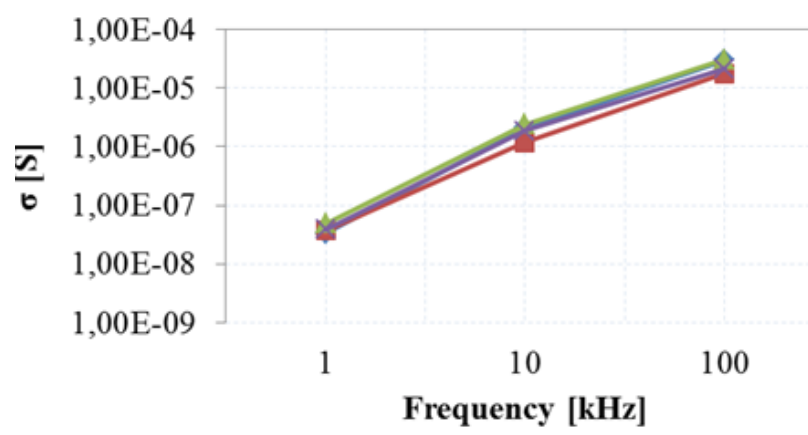

Fig. 4. Surface electrical conductivity of non-filled and filled epoxy matrices

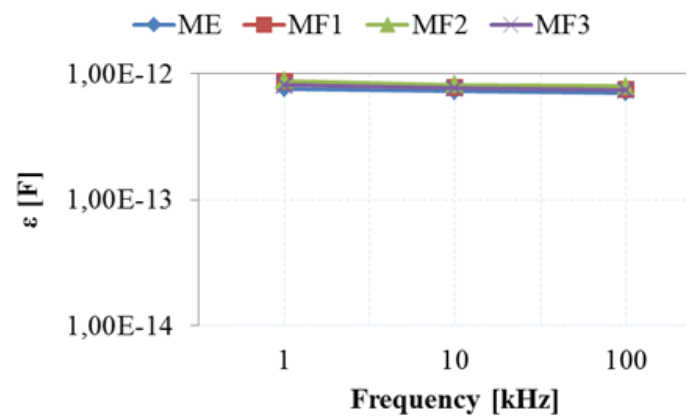

Fig. 5. Surface dielectric permittivity of non-filled and filled epoxy matrices

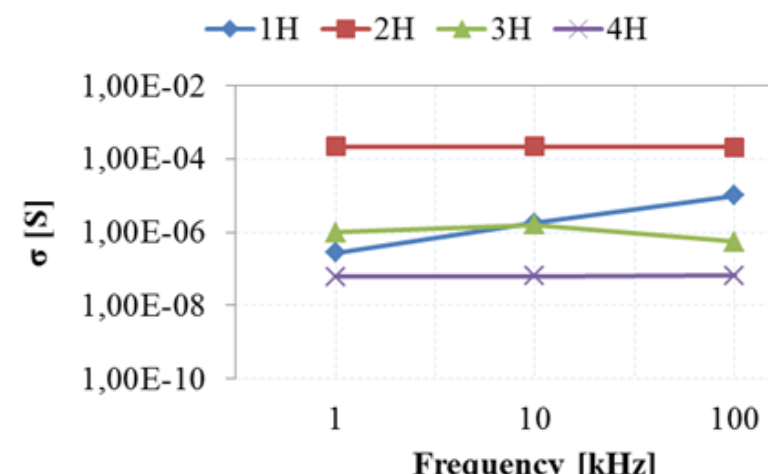

Fig. 6. Surface electrical conductivity of fabric reinforced hybrid composites with filled stratified epoxy matrix.

temperature range the mixtures made of aramid pow der, starch, carbon and glass whiskers (MF2) improved the thermomechanical behavior of epoxy matrix by decreasing the thermal expansion coefficient, offering an improvement of construction stability. With the increase of temperature, how itcan be observed for the $110^{\circ} \mathrm{C}-170^{\circ} \mathrm{C}$ temperature range, it was recorded the highest value of thermal expansion coefficient for non-filled epoxy matrix. On this temperature range the filled epoxy matrix with potatoes starch, carbon black (MF1) and aramid powder, barium ferrite (MF3) showed the same thermomechanical behavior, which was better than that of non-filled matrix. As per $40-60^{\circ} \mathrm{C}$ temperature range, the filled epoxy matrix with aramid powder, potatoes starch, carbon and glass whiskers (MF2) exhibited the lowest value of thermal expansion coefficient. So, the investigation of thermomechanical behavior of epoxy matrix showed that the fillers used in this research reduce the dilatation of epoxy materials with the increase of the temperature. Thereby, based on figure 3, it can be observed that the thermomechanical behavior of hybrid composites depends on the fiber orientation and carbon layers replacing with aramid layers. Generally, it can be seen that the hybrid laminates made of more aramid layers $(3 \mathrm{H}, 4 \mathrm{H})$ exhibit lower values of thermal linear expansion coefficient than those made of more carbon layers $(1 \mathrm{H}, 2 \mathrm{H})$ on both temperature ranges. Regarding the decrease of thermal expansion coefficient of hybrid composites by replacing of carbon layers with aramid layers impregnated with MF1 and MF3 epoxy matrix, the fiber orientation exhibited different effects on this coefficient. So, as in case of hybrid composites made of more carbon plies, the fiber orientation at various angles led to decreasing of thermal expansion coefficient on both temperature ranges. But the hybrid laminates made of more aramid plies and fiber orientation at $0^{\circ}(3 \mathrm{H})$ showed the low est values of this coefficient.

In graphs presented in figures 4-11, it can be noticed the effect of reinforcement layers, since the matrix is always

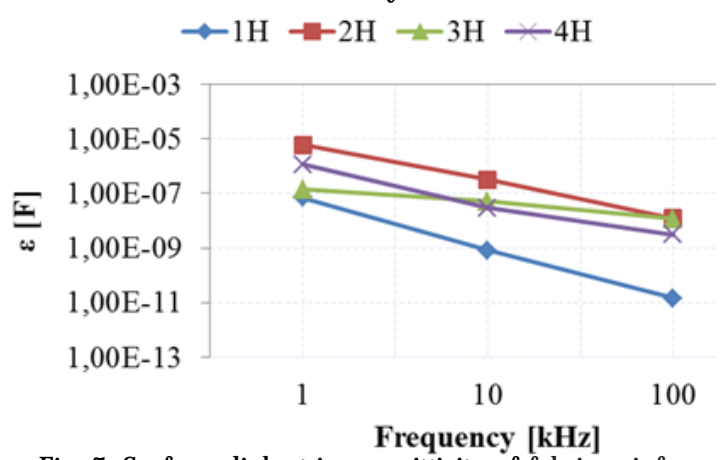

Fig. 7. Surface dielectric permittivity of fabric reinforced hybrid composites with filled stratified epoxy matrix $\rightarrow \mathrm{ME} \rightarrow \mathrm{MF} 1 \rightarrow \mathrm{MF} 2 \div \mathrm{MF} 3$

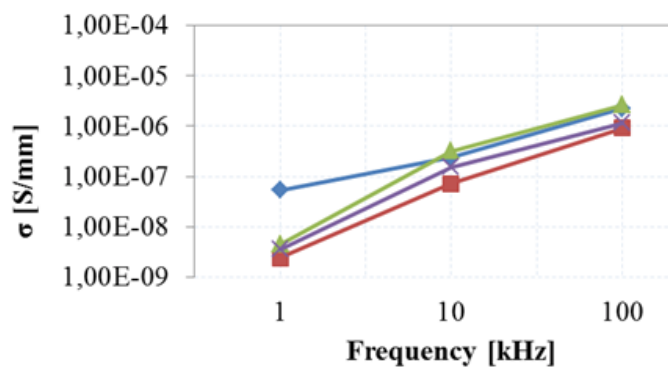

Fig. 8. Bulk electrical conductivity of non-filled and filled epoxy matrices

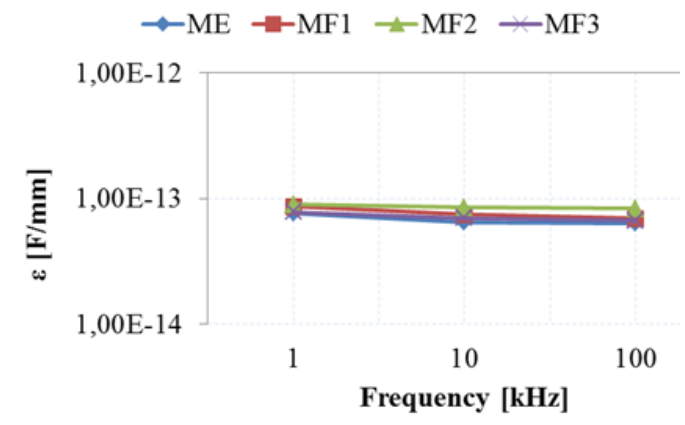

Fig. 9. Bulk dielectric permittivity of non-filled and filled epoxy matrices 


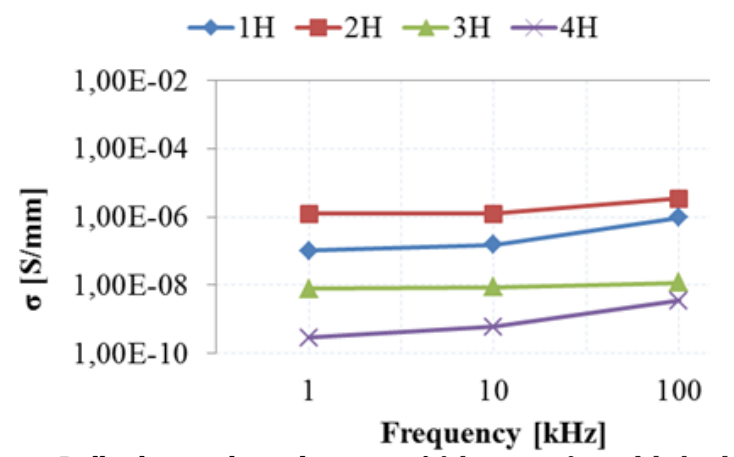

Fig. 10. Bulk electrical conductivity of fabric reinforced hybrid composites with filled stratified epoxy matrix.

the same, over the electrical behavior of hybrid composite plates and, also, might be noticed the frequency dependence of the studied parameters. The high capacity materials might be used to store electric energy while low resistance materials might be used to protect against electrical charge.

Based on obtained values from electrical measurements, there were calculated the dielectric permittivity and the electrical conductivity. For understand the electrical behavior of fabric reinforced hybrid composites with filled stratified epoxy matrix, it was performed the electrical measurements of plates made of non-filled and filled epoxy matrices. In figures 4 and 5 are plotted the surface electrical conductivity and dielectric permittivity of epoxy matrices. How it can be seen, the fillers did not influence the surface electrical behavior of epoxy matrix. The surface electrical conductivity of epoxy matrices increased with the increase of frequency, but the surface dielectric permittivity remained almost unchanged. So, as the surface electrical conductivity and dielectric permittivity of hybrid laminates depends on plies orientation and replacing of second outer carbon layers with aramid layers, even though for the first outer layers were used the carbon fabric (figs. 6, 7). Regarding the ply orientation of laminates, the surface electrical conductivity of composites with plies orientation at various angles showed the highest values for laminates with second outer carbon layers and the lowest values for those with second outer aramid layers (fig. 6). The surface conductivity of laminates with oriented plies at $0^{\circ}$ exhibited the values in the range of those of laminates with plies oriented at various angles. With increasing of frequency the surface electrical conductivity of laminates remained approximately unchanged, excepting the laminate with second outer carbon layer and fibers orientation at $0^{\circ}(1 \mathrm{H})$, which increases with the increase of frequency. Regarding the surface dielectric permittivity of hybrid composites, how it can be remarked in figure 7 , with increasing of frequency the values of this electrical parameter decrease for all laminates. The surface dielectric permittivity of hybrid composites with second outer aramid plies exhibits intermediate values in the range of those of hybrid composites with second outer carbon plies. In case of hybrid composites with second outer carbon layers, the materials with plies oriented at various angles showed the highest dielectric permittivity and the materials with plies oriented at $0^{\circ}$ showed the lowest dielectric permittivity. The laminate with second outer aramid plies and fiber orientation at $0^{\circ}(3 \mathrm{H})$ exhibited approximately the same values of dielectric permittivity of the laminate with second outer carbon plies and fiber orientation at $0^{\circ}(1 \mathrm{H})$ at the 1 $\mathrm{kHz}$ frequency, of the laminate with second outer aramid plies and fiber orientation at various angles $(4 \mathrm{H})$ at the 10 $\mathrm{kHz}$ frequency and of the laminate with second outer

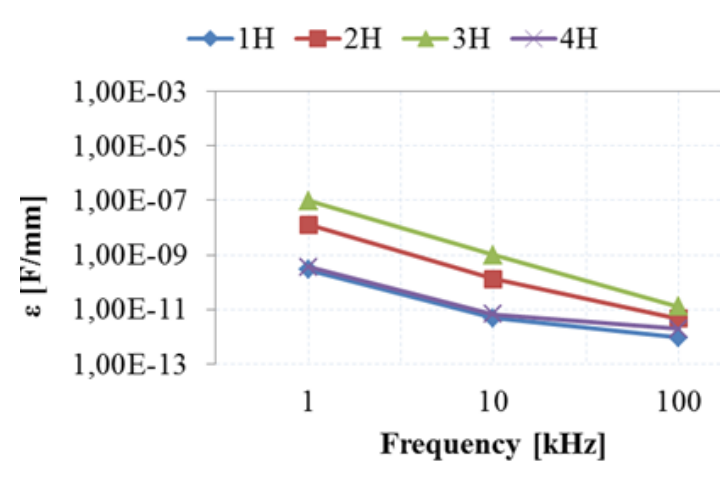

Fig. 11. Bulk dielectric permittivity of fabric reinforced hybrid composites with filled stratified epoxy matrix

carbon plies and fiber orientation at various angles $(2 \mathrm{H})$ at the $100 \mathrm{kHz}$ frequency.

The bulk electrical conductivity and dielectric permittivity of epoxy matrices are shown in figures 8 and 9 . As in the previous case, the epoxy matrices exhibited almost the same electrical behavior. The bulk electrical conductivity of matrices increased with the frequency, but at the $1 \mathrm{kHz}$ frequency the non-filled epoxy matrix showed a higher electrical conductivity than filled matrices (fig. 8). The dielectric permittivity of matrices decreased insignificantly with frequency increasing (fig. 9). Since the carbon is an electrical conductor, the laminates made of more carbon plies showed a higher electrical conductivity than the laminates made of more aramid plies (fig. 10). The fiber orientation of hybrid laminates exhibited different effects on the electrical conductivity. So, as the fiber orientation of hybrid laminates made of more carbon plies improved the bulk electrical conductivity while the fiber orientation of hybrid laminates made of more aramid plies led to decreasing of this electrical parameter. As it can be observed in figure 11, the bulk dielectric permittivity of all hybrid laminates decreased with frequency increasing. The hybrid laminate made of more aramid layers and fiber orientation at $0^{\circ}(3 \mathrm{H})$ exhibited the highest values of this parameter at all frequencies. The hybrid laminate made of more carbon layers and fiber orientation at $0^{\circ}(1 \mathrm{H})$ and the hybrid laminate made of more aramid layers and fiber orientation at various angles $(4 \mathrm{H})$ showed approximately the same electrical behavior.

\section{Conclusions}

The thermomechanical and electrical behavior of fabric reinforced hybrid laminates with filled stratified epoxy matrix was investigated. By analyzing of obtained data and plotted results in graphs above, it can be made the conclusions as follows:

The thermomechanical behavior of epoxy matrix can be improved by adding a mixture of fillers in epoxy resin composition. The lowest value of thermal linear expansion coefficient was showed for filled epoxy matrix with potatoes starch, aramid powder, carbon and glass whiskers on $40-60^{\circ} \mathrm{C}$ and $110-170^{\circ} \mathrm{C}$ temperature ranges. Regarding the electrical behavior of epoxy matrices, the used mixtures of fillers in epoxy matrix composition did not improve the electrical conductivity and dielectric permittivity, moreover the bulk electrical conductivity of non-filled epoxy matrix showed a higher value at the $1 \mathrm{kHz}$ frequency than those of filled epoxy matrix.

Regarding the influence of plies number of carbon and aramid in structure of hybrid laminates, it was found that the hybrid laminates made of more aramid layers showed lower values of thermal linear expansion coefficient on $40-60^{\circ} \mathrm{C}$ and $110-170^{\circ} \mathrm{C}$ temperature ranges than the hybrid 
laminates made of more carbon layers. But by increasing of carbon layers in laminates structure, it can be improved the electrical conductivity.

The influence of fiber orientation on improving of thermomechanical and electrical behavior of hybrid laminates, also, depends on number of carbon and aramid plies in structure of these materials. Thus, the fiber orientation at various angles of laminate made of more carbon plies led to decreasing of thermal linear expansion coefficient and increasing of electrical conductivity, while in case of laminate made of more aramid plies the influence of fiber orientation was reversely.

The values of electrical conductivity of laminates varied insignificantly with frequency increasing, excepting hybrid laminate made of more carbon plies and with fiber orientation at $0^{\circ} \mathrm{C}(1 \mathrm{H})$, whose surface electrical conductivity increased as well.

The dielectric permittivity of fabric reinforced hybrid laminates with filled stratified epoxy matrix decreased with frequency increasing.

\section{References}

1.BIRSAN I.G. et al., Fabric Reinforced Epoxy Composites, Annals of DAAAM for $2009 \&$ Proceedings of the 20th International DAAAM Symposium, vol. 20, no. 1, pp. 1683-1684, 2009.

2.BRIA V., CIRCIUMARU A., BIRSAN I.G., Some Properties of Starch/ Epoxy Composites, Mat. Plast., 48, no. 2, 2011, p. 189-194

.3.BIRSAN I.G., ROMAN I., BRIA V., UNGUREANU V., CIRCIUMARU A., Starch - Epoxy composites, Annals of DAAAM for 2011 \&Proceedings of the 22nd International DAAAM Symposium Intelligent Manufacturing \& Automation: Power of Knowledge and Creativity, pp. 285-286, 2011. 4.CIRCIUMARU A., BIRSAN I.G., ANDREI G., BRIA V., POSTOLACHE I., Some Properties of a Special Type of Reinforced Composites with Filled Epoxy, Academic Journal of Manufacturing Engineering, vol. 8, no. 1, pp. 30-36, 2010.

5.CIRCIUMARU A., BIRSAN I.G., BRIA V., UNGUREANU V., Thermomechaical and electrical properties of filled epoxy reinforced composites, Proceedings of 12th International Conference, pp. 159164, 2009.

6.AGARWAL G., PATNAIK A., SHARMA R.K., Mechanical and thermomechanical properties of bi-directional and short carbon fiber reinforced epoxy composites, Journal of Engineering Science and Technology, vol. 9, no. 5, pp. 590-604, 2014.
7.C. CAPELA, S. E. OLIVEIRA, J . A. M. FERREIRA, Mechanical behavior of high dosage short carbon fiber reinforced epoxy composites, Fibers and Polymers, vol. 18, no. 6, pp. 1200-1207, J un. 2017.

8.S.-Y. FU, B. LAUKE, E. MADER, C.-Y. YUE, X. HU, Tensile properties of short-glass-fiber- and short-carbon-fiber-reinforced polypropylene composites, Composites Part A: Applied Science and Manufacturing, vol. 31, no. 10, pp. 1117-1125, Oct. 2000.

9A. KAUSHIK, P. SINGH, J. KAUSHIK, The Mechanical Properties and Chemical Resistance of Short Glass-Fiber-Reinforced Epoxy Composites, International Journal of Polymeric Materials, vol. 55, no. 6, pp. 425-440, Jun. 2006.

10.I. ISLAM, S. SULTANA, S. KUMER RAY, H. PARVIN NUR, M. HOSSAIN, W. MD. AJMOTGIR, Electrical and Tensile Properties of Carbon Black Reinforced Polyvinyl Chloride Conductive Composites, Journal of Carbon Research, vol. 4, no. 1, p. 15, Feb. 2018.

11.N. ABDEL-AAL, F. EL-TANTAWY, A. AL-HAJ RY, M. BOUOUDINA, Epoxy resin/plasticized carbon black composites. Partl. Electrical and thermal properties and their applications, Polymer Composites, vol. 29, no. 5, pp. 511-517, May 2008.

12.N. PROBST E. GRIVEI, Structure and electrical properties of carbon black, Carbon, vol. 40, no. 2, pp. 201-205, Feb. 2002.

13.P. E. KHIZHNYAK, A. V. CHECHETKIN, A. P. GLYBIN, Thermal conductivity of carbon black, Journal of Engineering Physics, vol. 37, no. 3, pp. 1073-1075, Sep. 1979.

14.Z. M. ELIMAT et al., Dielectric properties of epoxy/short carbon fiber composites, Journal of Materials Science, vol. 45, no. 19, pp. 5196-5203, Oct. 2010.

15.SHETH CHETAN, PAREKH B.R., MANOCHA L.M., SHETH PARUL, Effect of Chopped Carbon Fiber on Electrical and Thermal properties of Carbon Reinforced Epoxy Composites, International J ournal of Advanced Research in Electrical, Electronics and Instrumentation Engineering, vol. 2, no. 11, pp. 5551-5562, 2013.

16.C. MUNTENITA, C., BRIA, V., ENI, C., CIRCIUMARU, A., GRAUR, I., Physical Characterization of Nano-ferrites Modified Epoxy Resins, Mat. Plast., 53, no. 3, 2016, p. 509-511

17.C. MUNTENITA, C. UNGUREANU, V. BRIA, I. GRAUR, Specific heat of nano-ferrites modified composites, MATEC Web of Conferences, vol. 112, p. 04016, 2017.

18.BUNEA, M., IOAN, B., BOSOANCA, R., MARIUS,B., CIRCIUMARU, $A$.,Bending and Compressive Properties of Fabric Reinforced Composites, Mat. Plast., 52, 2015, p. 368-372

19.BUNEA, M., BOSOANCA, R., ENI, C., CRISTACHE, N., STEFANESCU, $V$., The impact characteristics of fabric reinforced hybrid composites, Mat. Plast., 54, 2017, p. 286-290

Manuscript received: 15.06 .2018 